\title{
Breast Hamartoma: A Size Diversity with Psychosocial Impact Analysis of 20 Cases and an Exceptional Case Report Review
}

Afsheen Javaid Khokher', Rufina Soomro ${ }^{2 *}$

${ }^{1}$ Department of Surgery, Liaquat National Hospital and Medical College, Karachi, Pakistan.

${ }^{2}$ Department of Surgery, Liaquat National Hospital and Medical College, Karachi, Pakistan.

\author{
"Correspondence author \\ Rufina Soomro, \\ Department of Surgery \\ Liaquat National Hospital and Medical College Karachi \\ Pakistan
}

Submitted : 2 Sept 2020 ; Published : 4 Oct 2020

\begin{abstract}
Objectives: Breast hamartoma is a rare painless benign tumor with limited literature review due to underestimation by clinicians and pathologists. Though slowly growing, delay in diagnosis can lead to physical and psychological impact due to breast size discrepancy. Our study intend was to present breast hamartoma concerning size variance from hardly palpable to gross defacement and its psychosocial impact due to physical disfigurement, along with a case report.

Method: We reviewed the demographic data, radiological imaging, and size variability of patients diagnosed with breast hamartoma between May 2006 and November 2019.

Results: Overall, 37 cases of female breast hamartoma were operated from 2006 to 2019 but only 20 cases, whose data can be retrieved, in Liaquat National Hospital \& Medical College, Karachi Department of General Surgery were included in the study. The mean age of patients was $35 \pm 11.92$ years. The clinical and histopathological size was $6.12 \pm 4.44$ and 7.88 \pm 4.23 respectively. Largest recorded size was $20 x 20 \mathrm{~cm}$. There are $65 \%$ of cases with less than 40 years and $35 \%$ cases with greater than 45 years. Breast ultrasound and Mammograms were performed below 40 years and greater than 40 years age of respectively. Furthermore, one case presented with skin necrosis and necrotizing wound infection underwent wound debridement and later on reduction mammoplasty with hamartoma excision of $2.5 \mathrm{~kg}$.

Conclusion: Breast hamartomas are rare benign lesions that may have rapid growth leading to breast disfigurement and must be addressed vigilantly either by close observation or early intervention. Ultrasound has a significant role in diagnosis whereas the role of fine-needle aspiration is questionable.
\end{abstract}

Keywords: Breast, Hamartoma, necrotizing wound infection.

\section{Introduction}

Breast hamartoma also is known as fibroadenolipoma is a rare benign condition of indeterminate cause and pathogenesis [1]. Due to its rarity and benign nature, it is usually undiagnosed or has delayed diagnosis [2].

Hamartomas represent only $0.1-0.7 \%$ of benign breast lesions in women [3]. The majority of cases are $>35$ years old, with a mean age of 45 years. Breast hamartomas have a wide range of clinical presentations ranging from accidental radiological diagnosis to painless, slowly growing tumors which can range from pea size to a melon size leading to gross breast deformity [4].
The diagnostic investigation involved is ultrasound, mammogram, and MRI breast. Sonographically it is wellcircumscribed heterogeneous masses with a pseudo capsule [5].

Treatment depends upon the clinical presentation of the patient from reassurance to surgical excision. These lesions grow slowly and could become bigger if no intervention is given, which results in morbidities like breast hypertrophy, disfigurement leading to psychological effect, compressive symptoms causing skin necrosis, ulceration, and lymphedema [6]. 
In this review, we have discussed our experience of 20 cases hamartoma concerning the diversity of patient presentation and size variability. We had a focus on a case of hamartoma creating misery in patient's life due to physical disfigurement by its breast asymmetry and highlight diagnostic difficulties and the importance of early intervention.

\section{Methods}

Between 2006 and 2019, a total of 37 patients operated and biopsy reported as breast hamartoma was collected from the Breast Division of General Surgery Department of Liaquat National Hospital and Medical College, Karachi Pakistan. We were able to retrieve data of 20 out of 37 patients including clinical presentation, radiological investigation, and histopathological reports from hospital records.

\section{Results}

The mean age of patients was $35 \pm 11.92$ years. The clinical and histopathological size was found as $6.12 \pm 4.44$ and $7.88 \pm 4.23$ respectively. There are $65 \%$ of cases with less than 40 years and $35 \%$ cases with greater than 45 years. The ultrasound and mammogram screening was done in $50 \%$ cases and $15 \%$ cases respectively. On ultrasound, hamartoma was diagnosed in $20 \%$ cases. Whereas in the rest of the cases it was labeled as benign fibroadenoma or suspicious abnormality. The detailed results are mentioned in Table 1.

\begin{tabular}{|c|c|}
\hline Characteristics & $\mathrm{n}(\%)$ \\
\hline Age $($ Mean \pm SD $)$ & $35 \pm 11.92$ \\
\hline Clinical size $($ Mean \pm SD) & $6.12 \pm 4.44$ \\
\hline $\begin{array}{l}\text { Histopathological size } \\
(\text { Mean } \pm \text { SD) }\end{array}$ & $7.88 \pm 4.23$ \\
\hline \multicolumn{2}{|l|}{ Age group } \\
\hline$<40$ years & $13(65)$ \\
\hline$>40$ years & $7(35)$ \\
\hline Ultrasound & $10(50)$ \\
\hline Mamogram & $3(15)$ \\
\hline \multicolumn{2}{|l|}{ Ultrasound diagnosis } \\
\hline Yes & $4(20)$ \\
\hline No & $16(80)$ \\
\hline \multicolumn{2}{|l|}{ Associated pathology } \\
\hline $\begin{array}{l}\text { Contralateral side breast } \\
\text { cancer }\end{array}$ & $2(10)$ \\
\hline \multicolumn{2}{|l|}{ Histopathology } \\
\hline FNAC & $3(15)$ \\
\hline Trucut biopsy & $4(20)$ \\
\hline \multicolumn{2}{|l|}{ Clinical Presentation } \\
\hline Pain & $2(10)$ \\
\hline Painless lump & $15(75)$ \\
\hline Breast Asymmetry & $3(15)$ \\
\hline
\end{tabular}

Table 1 : Descriptive Statistics
The most common presentation was painless, soft-to-firm, palpable breast lumps and three patients had breast asymmetry and 1 patient had rare presentation admitted in an emergency with gross breast Asymmetrization leading to skin pressure ulcer and necrotizing infection and high-grade fever as discussed in detailed in case report below. Breast ultrasonography (US) was performed on all of the patients below 40 years of age, as the first preoperative imaging procedure and mammogram was done in patients above 40 years of age. 3 patients FNAC was done in which 2 showed benign hyperplasia and 1 showed histiocytes with adipocytes.

Trucut biopsy was done in 4 patients, which showed benign proliferative ductal hyperplasia. No one diagnosed hamartoma. 2 patients had contralateral site breast cancer .1 had the previous history of breast cancer and hamartoma is identified on follow up mammograms. The other was diagnosed at the same time in the contralateral breast.

Our results showed that ultrasound has a significant association in the diagnosis of hamartoma $(p=0.01)$ as compared to Mammogram screening $(p=0.001)$ respectively. The detailed results are mentioned in table 2 .

\begin{tabular}{|c|c|c|c|}
\hline & \multicolumn{2}{|c|}{ Age group } & \multirow[t]{2}{*}{$\mathrm{p}$-value } \\
\hline & $<40$ years & $>40$ years & \\
\hline \multicolumn{4}{|c|}{ Ultrasound } \\
\hline Yes & $8(61.5)$ & $2(28.6)$ & \multirow[b]{2}{*}{$0.155^{* *}$} \\
\hline No & $5(38.5)$ & & \\
\hline \multicolumn{4}{|c|}{ Mammogram } \\
\hline Yes & $0(0)$ & $3(42.9)$ & \multirow[b]{2}{*}{$0.007 *$} \\
\hline No & $13(100)$ & $4(57.1)$ & \\
\hline
\end{tabular}

Table 2 : Association of different screening test with age

Chi-square test is applied. groups

*Significant at $\mathrm{p}$-value $<0.05$

**Insignificant at $\mathrm{p}$-value $>0.05$

\section{Case}

A 25-year-old female, presented in the Emergency Department with painful enlarged left breast with non-healing wounds, and started spiking fever high-grade fever for the last 1 month.

On physical examination, an ill-looking, anxious girl with markedly enlarged left breast with fowl smelling necrotizing skin wound extending into the axilla and infra-mammary fold (fig 1, 2, 3). There was no palpable lump however breast tissue was hanging below umbilicus leading to skin thinning and ulceration. She was febrile with a documented fever of $102 \mathrm{~F}$ Right breast examination was normal. Total leucocyte count of $26,000 / \mathrm{c} \mathrm{mm}$. Ultrasound breast showed inflammatory changes with no breast mass. She underwent debridement and broad-spectrum antibiotics were started. 


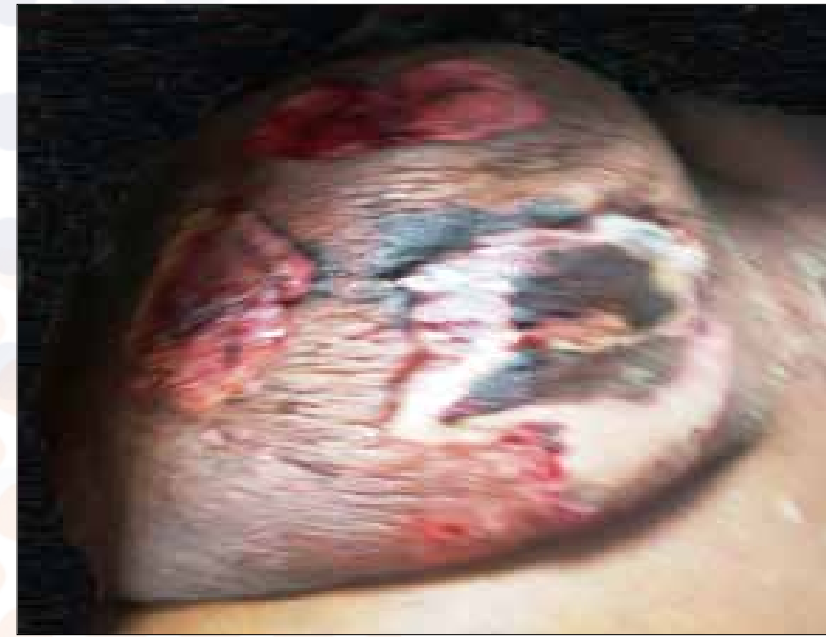

Figure 1: left breast lateral surface skin ulceration \& necrosis

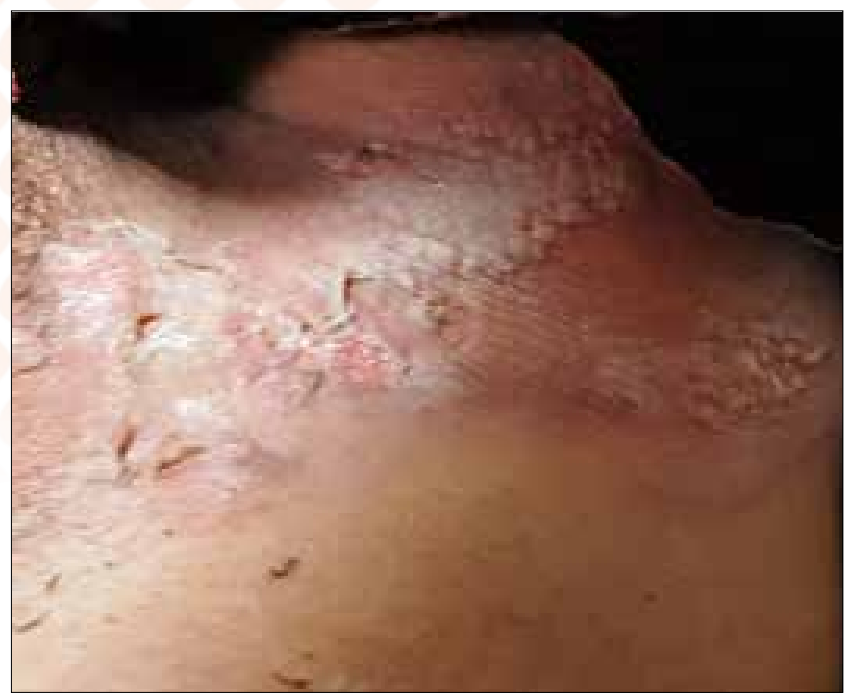

Figure 2: Skin blebs extending even beyond the breast

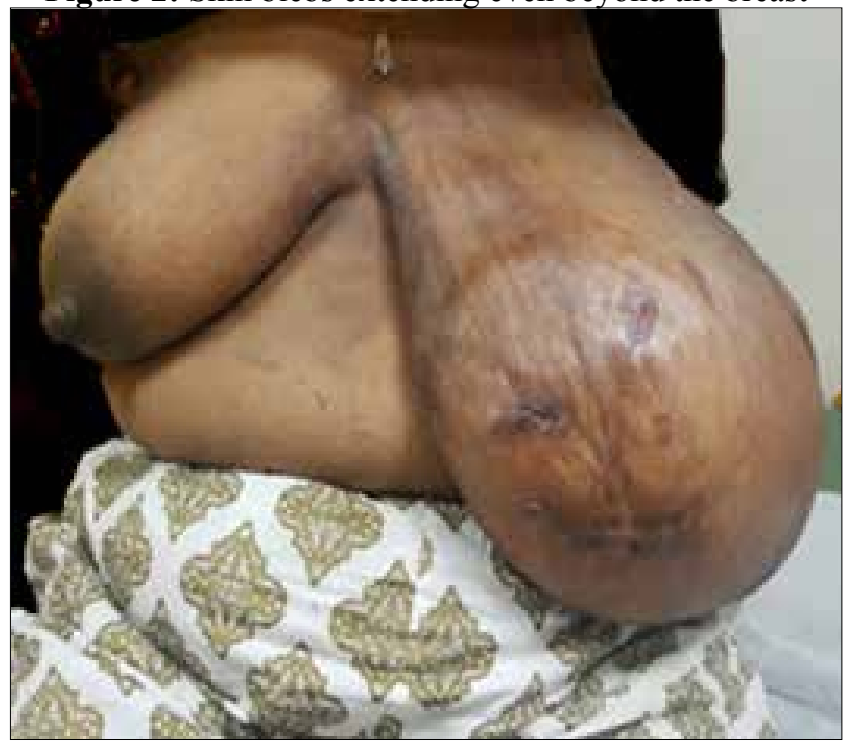

Figure 3: Massively enlarged left Breast

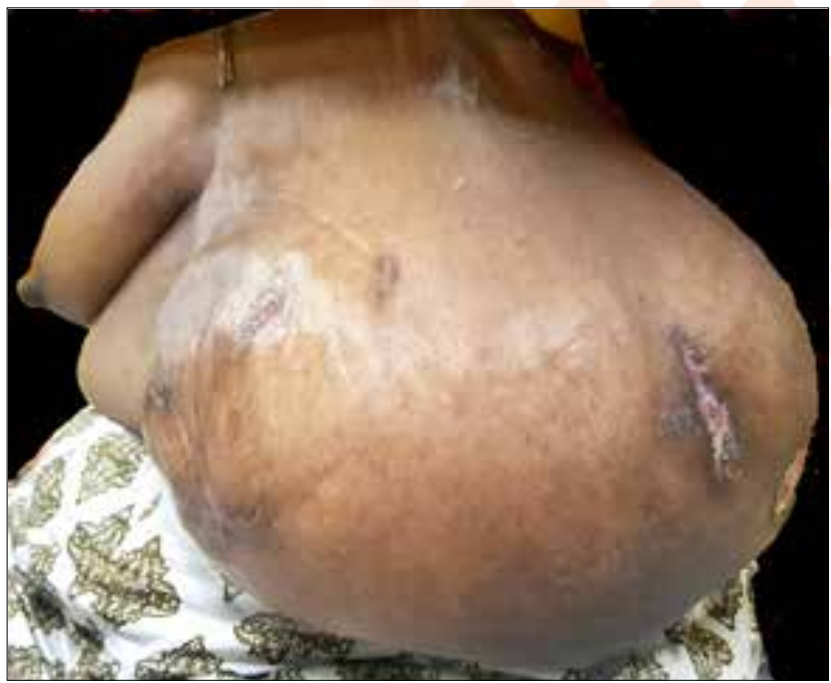

Figure 4: Healed wounds at the lateral aspect

On inquiring patient has rapid enlargement of the left breast for 3 years. There was no history of breast trauma or surgery. She has visited multiple doctors for breast asymmetry. She has been experiencing significant pain and debilitation due to the size and weight of the mass. She was depressed and upset about her size change and she would completely cover herself and avoid social interaction completely because she could not face people.

In the previous radiological investigation, an ultrasound showed hypertrophied breast tissue with no definite mass lesion in the breast. However, due to inflammatory changes and marked edema biopsy was advised, which showed benign hypertrophied breast tissue with hyperplasia and nonspecific inflammation. With antibiotics and local care patient's wounds healed with scar tissue in 2 months. Repeat ultrasound and Mammogram was done. The patient was planned for left-sided reduction mammoplasty to relive patient misery and pressure necrosis due to massively enlarged left breast.

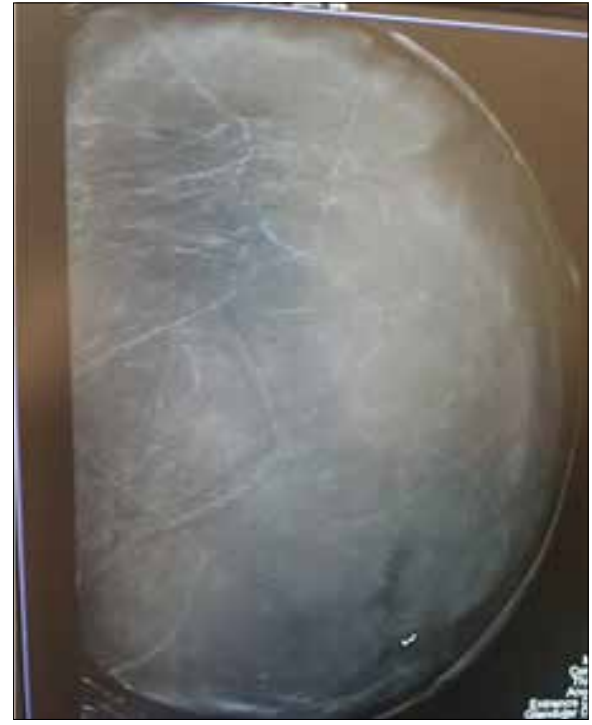

Figure 5: mammogram $\mathrm{CC}$ view 


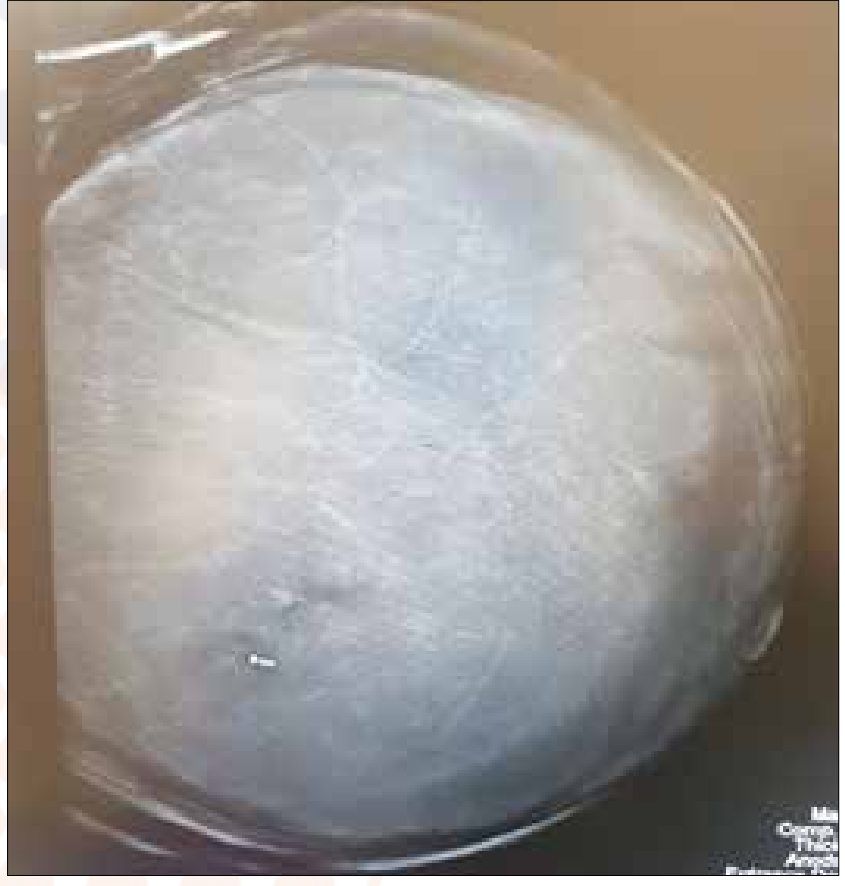

Figure 6: mammogram MLO view

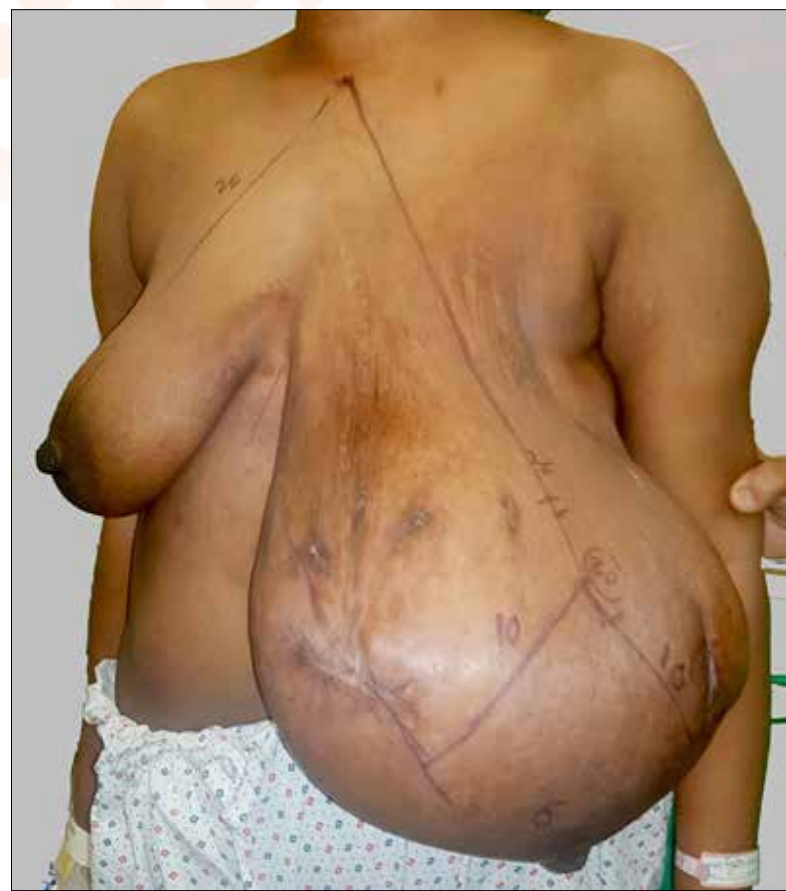

Figure 7: Breast marking before the surgery

The operative finding showed well defined encapsulated soft mass of about $20 \times 20 \mathrm{~cm}$ with a weight of $2.5 \mathrm{~kg}$. Excision of mass with Reduction Mammoplasty done.

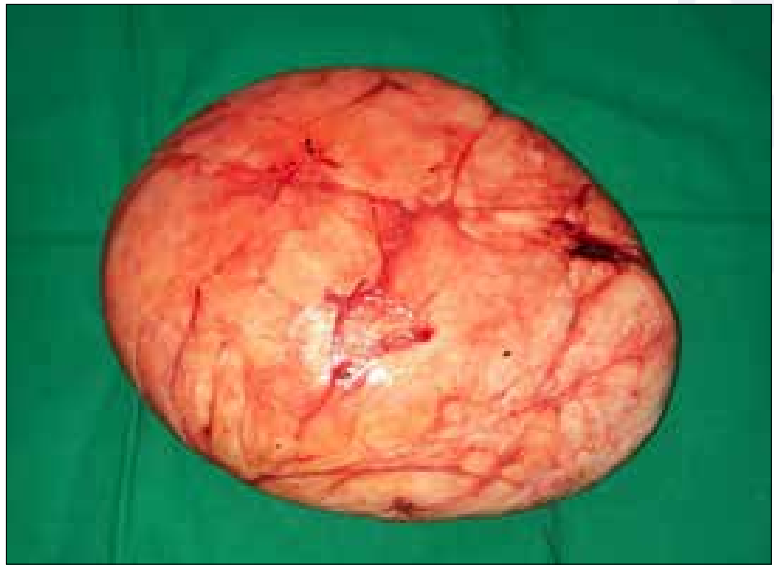

Figure 8: Well defined mass excised from the breast
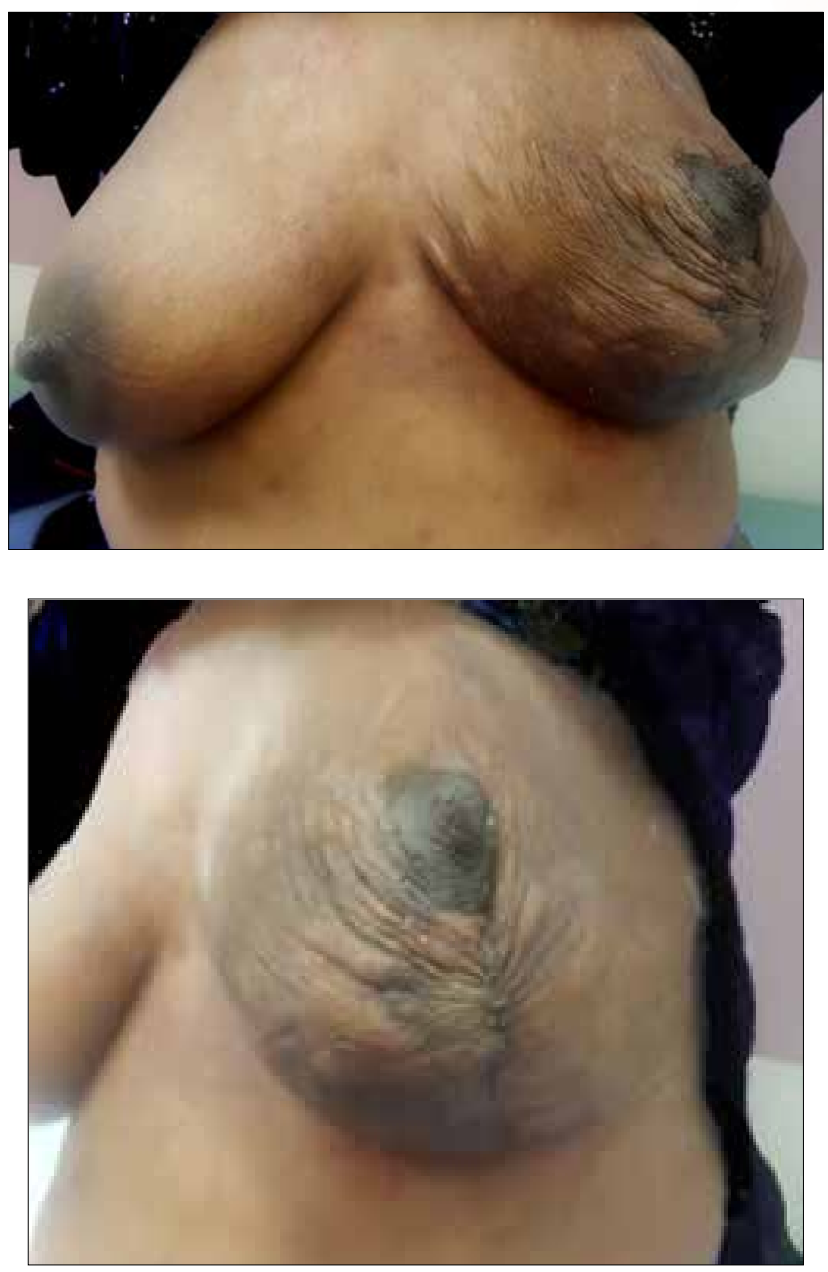

Figure 9 \& 10: Post- operative picture

Histopathology

Pathologic evaluation of the $21 \mathrm{~cm} \times 16 \mathrm{~cm} \times 10 \mathrm{~cm}$ gross wellcircumscribed lesion, weight of $2.5 \mathrm{~kg}$. On sectioning, tissue had a relatively homogeneous appearance. Histologically, disordered arrangements of breast ducts, few of them are dilated lined by dual cell layers. At some places adipose tissue with background stromal fibrosis was present. Features favor hamartoma. 

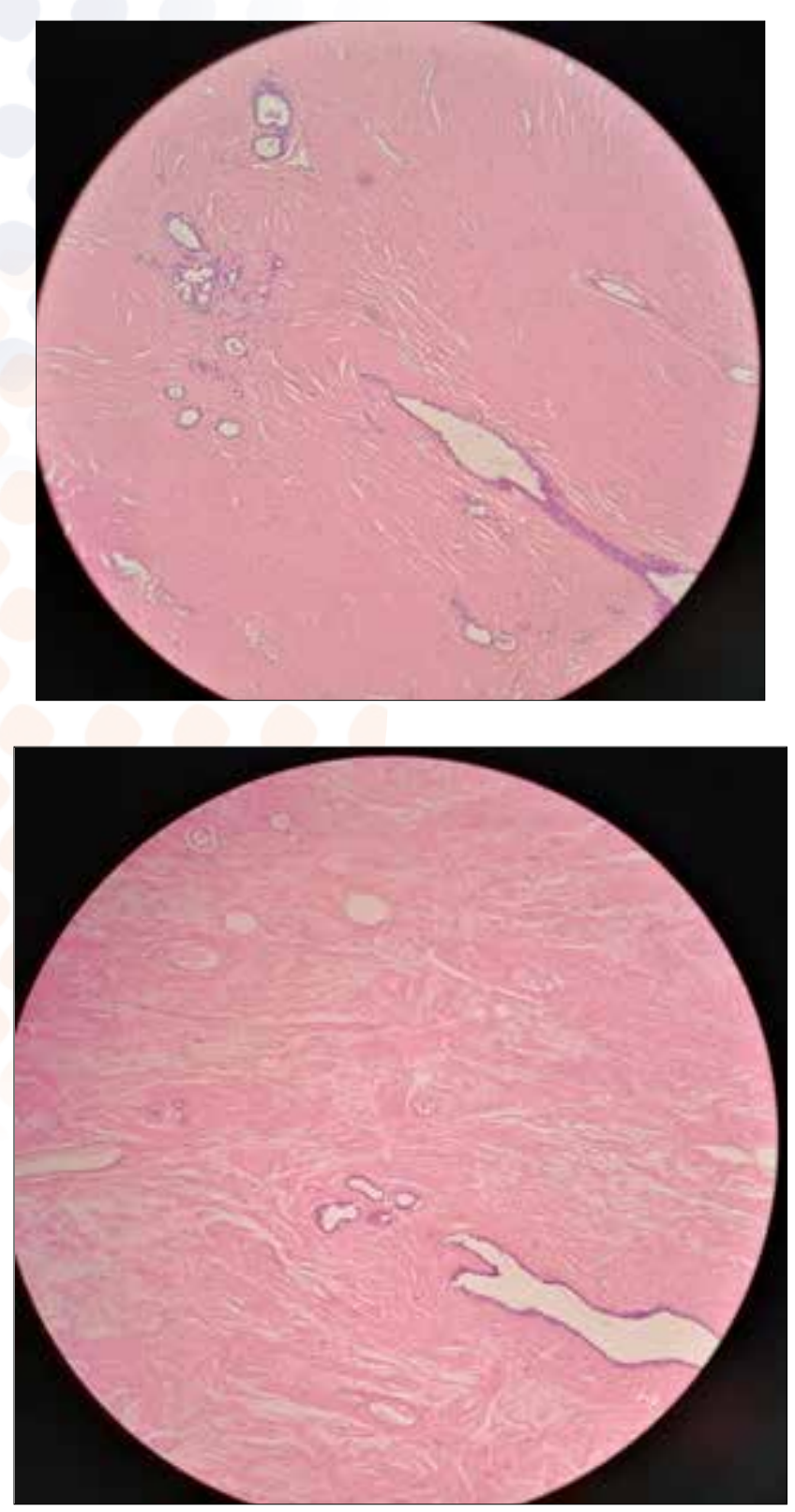

Figure 11: Histo-pathology slide view

Discussion

Breast hamartomas are ill-defined, rare, benign breast tumor that contains normal breast parenchyma including fibrous, fibrocystic, and adipose tissue [7].

Differential diagnosis may include fibroadenoma, phyllodes tumor lipoma, fat necrosis, adenomyoepithelioma, cystadenoma, leiomyoma [8].

In literature, hamartomas are common on average age of 45 years but in our study, more than $65 \%$ of patients are below 40 and the average age was 35 years. This is in favor of its young age disease. Clinically hamartomas are usually small but they may manifest as large mobile well defined, consistency is soft to firm [9]. They are slowly growing but could become larger enough to cause physical disfigurement as in our case if no intervention is done [10].
Delayed or missed diagnosis is due to its fibro-fatty nature which resembles normal breast tissue or fibroadenoma. The diagnosis of breast hamartoma by a single radiological investigation such as mammography, magnetic resonance imaging, or sonography is inadequate and needs more than one investigation [11]. Our study showed a significant association of diagnosis with ultrasound not with the mammogram.

Due to fatty nature some time sonographically it can be missed as in our case the mass was encompassing the entirety of the breast so the ultrasound was read as "normal tissue" [12]. On mammography, these lesions are ovoid, heterogeneous parenchymal density with hypodense fat-containing areas with thin pseudo-capsule. It can present as mixed density masses on mammography with fat and soft tissue densities and benign calcification [13].

Hamartomas do not own specific diagnostic histologic features; therefore diagnosis is difficult, especially on biopsy or FNAC [14]. This is evident from our study, neither FNAC nor trucut biopsy gives the diagnosis of hamartoma. The role of percutaneous biopsy for diagnosis of hamartoma is limited [15].

There is a small incidence of approximately $0.1 \%$ of malignancy found within hamartomas [16-18]. Two of our patients had cancer in the contralateral breast. Unusual morbidity of breast asymmetry and physical disfigurement can cause life-long psychosocial impact, resulting in loss of self-confidence and interfering with social relationships, as evident by our case report $[19,20]$. After surgery, she was the happiest person that she can live a normal life and socialize and get married.

Though benign but critical psychosocial impact and risk of malignancy (though rare) is the need of raising red flags for early diagnosis and timely intervention. In cases of breast asymmetry, Hamartoma should be considered in the differential diagnosis. When initial workup fails to reveal a more common etiology and benign tumor is still suspected, hamartoma should not be missed.

\section{Conclusion}

Early diagnosis and timely intervention of hamartoma will result in proper management, decreased morbidity, and diminished psychosocial sequelae.

\section{References}

1. Charpin C, Mathoulin MP, Andrac L, Barberis J, Boulat J, Sarradour B, et al (1994). Reappraisal of breast hamartomas. A morphological study of 41 cases. Pathol Res Pract, 190(4), 362-371. http://dx.doi.org/10.1016/ S0344-0338(11)80408-5.

2. Venkatesh MS, Harish K (2009). Giant breast hamartoma. Indian J Surg, 71, 50-51.

3. Guray M, Sahin AA (2006). Benign breast diseases: Classification, diagnosis, and management. Oncologist, 11(5), 435-449. 
4. Birrell AL, Warren LR, Birrell SN (2012). Misdiagnosis of massive breast asymmetry: giant hamartoma. ANZ $J$ Surg, 82, 941-942.

5. D Adler, DO Jeffries, MA Helvie (1990). Sonographic features of breast hamartomas. J Ultrasound Med, 9, 8589.

6. Weinzweig N, Botts J, Marcus E (2001). Giant hamartoma of the breast. Plast Reconstr Surg, 107, 1216-1220.

7. Prym P. Pseudoadenome, Adenome und Mastome der weiblithen Brustdrfise (1928). Studien fiber die Entstehung umschriebener adenom, hnlicher Herde in der Mamma und fiber die Nachahmung der Brustdrfisengewebes durch echte Adenome und Fibroadenome. Beitr Pathol Anat, 81, $1-44$.

8. Mizuta N, Sakaguchi K, Mizuta M, Imai A, Nakatsukasa $\mathrm{K}$, Morita M, et al (2012). Myoid hamartoma of the breast that proved difficult to diagnose: a case report. World $J$ Surg Oncol, 10, 12.

9. Ruiz Tovar J, Reguero Callejas ME, Alaez Chillaron AB, et al (2006). Mammary hamartoma. Clin Transl Oncol, 8, 290-293.

10. Bhatia M, Ravikumar R, Maurya VK, Rai R (2015). "Breast within a breast" sign: Mammary hamartoma. Med J Armed Forces India, 71(4), 377-379.

11. Farrokh D, Hashemi J, Ansaripour E (2011). Breast hamartoma: Mammographic findings. Iran J Radiol, 8, 258-260.

12. Chao TC, Chao HH, Chen MF (2007). Sonographic features of breast hamartomas. JUM, 26, 447-452.

13. Helvie MA, Adler DD, Rebner M, Oberman HA (1989). Breast hamartomas: Variable mammographic appearance. Radiology, 170, 417-421.

14. Herbert M, Mendlovic S, Liokumovich P, Segal M, Zahavi S, Rath-Wolfson L, Sandbank J (2006). Can hamartoma of the breast be distinguished from fibroadenoma using fine-needle aspiration cytology? Diagn Cytopathol, 34, 326-329.

15. Tse GM, Law BK, Ma TK, et al (2002). Hamartoma of the breast: a clinicopathological review. J Clin Pathol, 55, 951-954.

16. Lee EH, Wylie EJ, Bourke AG, Bastiaan De Boer W (2003). Invasive ductal carcinoma arising in a breast hamartoma: two case reports and a review of the literature. Clin Radiol, 58, 80-83.

17. Mester J, Simmons RM, Vazquez MF, Rosenblatt R (2000). In situ and infiltrating ductal carcinoma arising in a breast hamartoma. AJR Am J Roentgenol, 175, 64-66.

18. Franco Uliaque C, Pardo Berdun FJ (2010). Carcinoma in situ and invasive carcinoma within a breast hamartoma. Radiologia, 52, 487-488.

19. S. Cazorla, C. Arentz (2015). Breast hamartomas e Differential consideration in slow developing breast asymmetry. JPRAS Open, 3, 17-21.

20. Birrell AL, Warren LR, Birrell SN (2012). Misdiagnosis of massive breast asymmetry: giant hamartoma. ANZ J Surg, 82, 941-942.

Copyright: (C2020 Rufina Soomro. This is an open-access article distributed under the terms of the Creative Commons Attribution License, which permits unrestricted use, distribution, and reproduction in any medium, provided the original author and source are credited. 